\title{
OS TRAÇOS FASCISTAS POR TRAS DO PRECONCEITO, VIOLÊNCIA E BULLYING NA ESCOLA.
}

\section{FASCIST TRAITS BEHIND PREJUDICE, VIOLENCE AND BULLYING INSIDE SCHOOL.}

Anilde Tombolato Tavares da Silva ${ }^{1}$

Cândida Alayde de Carvalho Bittencourt ${ }^{2}$

\begin{abstract}
Resumo
Este texto consiste em crítica contundente às condições sociais que geraram o fascismo e, dentro desse, à personalidade autoritária predisposta a preconceitos e consequentemente a atos de violência. A análise do preconceito e a violência na escola, permite entender como as representações da sociedade em que vivemos se reproduzem no cotidiano escolar - instituição que deveria ser o espaço de educação e socialização das crianças, mas que se transformou em espaço de agressão e desrespeito mútuo, com situações de preconceito, violência e bullying, como o uso de piadas e ofensas, formas de violência psicológica que são negativas para a formação e constituição da subjetividade e identidade das crianças. Esses, não devem ser tolerados e, necessitam ser enfrentados por professores, coordenadores e direção, com trabalhos educativos de desconstrução de estigmas. $O$ referido artigo traça caminhos reflexivos para identificar e combater o bullying, a manifestação do preconceito e contribuir na superação do pensamento estereotipado em relação às minorias vítimas do preconceito na escola, além de impactar a formação de educadores que vivenciam essa realidade no dia a dia nas salas de aulas.
\end{abstract}

Palavras chave: Educação; Preconceito; Personalidade Autoritária; Bullying.

\begin{abstract}
This text focus on a severe criticism to social conditions that result in fascism and, within that, to an authoritative personality inclined to prejudice and as a consequence to acts of violence. Analyzing prejudice and violence within a school, allow us to understand how the representations of the society which we live are recreated in the school environment - an institution that should be a space for education and socialization to children, but had become a space of reciprocal aggression and disrespect, happening situations of prejudice, violence and

\footnotetext{
${ }^{1}$ Professora Associada do Departamento de Educação da Universidade Estadual de Londrina. E-mail: anildetombolato@gmail.com

2 Professora Associada do Departamento de Arte Visual da Universidade Estadual de Londrina. E-mail: candida.carvalho@uel.br
}

Revista Devir Educação, Lavras, vol.3, n.1, p.116-126 jan./jun., 2019. 


\section{QO DEVIR EDUCAÇÃO \\ ISSN: 2526-849X}

bullying, using jokes and insults, psychological violence which is negative in the formation and constitution of a child's subjectivity and identity. These, should not be tolerated and, it is necessary to be faced by teachers, coordinators and school government, through educative work to deconstruct stigmas. This article reflects ways to identify and fight bullying, prejudice manifestation and contributes to overcome stereotyped thoughts related to minorities that are victims of prejudice inside the school, in addition to impact educator's formation from professionals who deal with this reality in their classrooms every day.

Key words: Education; Prejudice; Authoritative personality; Bullying

\section{Introdução}

A questão do preconceito e as ações para combatê-lo, é um tema muito recorrente em diversos meios, desde o acadêmico até instâncias governamentais e internacionais. Tal discussão se fundamenta pela necessidade de refletir sobre os traços fascistas que se escondem nas atitudes que se espalham cotidianamente nas escolas e fora delas. O texto pretende discutir o preconceito, a violência e o bullying presentes na escola, apoiados nos trabalhos de pensadores da Teoria Crítica da Sociedade e textos de Adorno e Horkheimer. É uma crítica contundente às condições sociais que geraram o fascismo e, dentro desse, à personalidade predisposta a preconceitos e consequentemente a atos de violência. Entre estes textos cabe ressaltar: "La personalidade Autoritaria" de 1965, "Elementos do Anti semitismo", publicado na Dialética do Esclarecimento, em 1947; "Mínima Moralia: Reflexões a partir da vida danificada", de 1951 e "Eclipse da Razão", de Horkheimer, de 1946. Textos que consistem em crítica contundente às condições sociais que geraram o fascismo. Leituras que nos instigam a colocar em dúvida as disposições psicológicas na abordagem adotada nos traços da personalidade autoritária, dentro de um fenômeno complexo e dinâmico que se constrói entre indivíduo e sociedade. Nossa compreensão apoia-se na citação de Adorno e Horkheimer (1973), ao afirmarem que:

As grandes leis do movimento social não regem por cima das cabeças dos indivíduos, realizando-se sempre por intermédio dos próprios indivíduos e de suas ações. A investigação sobre o preconceito tende a reconhecer a participação do movimento psicológico nesse processo dinâmico em que operam a sociedade e o indivíduo. (p.173-174)

Revista Devir Educação, Lavras, vol.3, n.1, p.116-126 jan./jun., 2019. 


\section{QO DEVIR EDUCAÇÃO \\ ISSN: 2526-849X}

Um processo dinâmico em que as características do sujeito potencialmente preconceituoso são adquiridas durante o seu processo de socialização e, portanto não são inatas - são psicossociais e atuam na formação e sustentação das representações psicológicas e no comportamento etnocêntrico do sujeito, contribuindo na formação complexa das características e diversidade nas estruturas autoritárias da personalidade. Neste sentido, podemos afirmar que existem vários tipos de sujeitos autoritários, conforme a prevalência de uma ou mais destas estruturas. Desta forma, entende-se que os traços fascistas, transvestidos pela violência escolar é derivada de uma violência social, quando se apresenta em suas especificidades, e diretamente social, quando traz problemas sociais de diversas naturezas para dentro dos muros escolares.

$\mathrm{O}$ arquétipo da personalidade potencialmente fascista e autoritária se estrutura, de forma resumida, em algumas características tais como: adesão ao ideário burguês, submissão acrítica nas relações com autoridade moral, agressividade autoritária, hostilidade e desprezo às humanidades, ênfase nas relações de dominação-submissão, superstição e estereotipia, oposição à subjetividade, projeção e preocupação excessiva com a sexualidade. (ADORNO et al., 1965).

Diante da urgente necessidade de levantar e tecer um diagnóstico crítico em relação à predominância cada vez maior desse tipo de racionalidade buscamos compreender os mecanismos que são articulados para cometer atos preconceituosos e violentos dentro e fora dos muros escolares e, contribuir na superação do pensamento estereotipado em relação às minorias vítimas do preconceito na escola, além de promover o debate e a formação de educadores que vivenciam essa realidade no dia a dia nas salas de aulas.

\section{Fascismo e Personalidade Autoritária}

Os estudos sobre o preconceito estão conectados, historicamente, ao surgimento e ao estabelecimento da ideologia nazi-fascista. A obra La Personalidad Autoritaria elaborado por uma equipe de pesquisadores formada por filósofos, sociólogos, psicanalistas, liderados por Adorno, da Universidade de Berkeley, fruto de diversas pesquisas realizadas na década de 1940, permitiu a identificação dos traços de personalidade potencialmente fascista através de instrumentos, que mensuravam e identificavam os traços presentes em indivíduos com este tipo de personalidade. Nestes estudos, os pesquisadores elaboraram a "Escala F", um indicador empírico em que através de questionários e entrevistas clínicas procuraram 


\section{OO DEVIR EDUCAÇÃO}

ISSN: 2526-849X

identificar o potencial fascista de indivíduos comuns numa sociedade massificada. Nesta escala, o tipo psicológico radicado no seu nível mais elevado é caracterizado por Adorno como fascista.

Os autores tomaram como ponto de partida a discriminação social, mas seu propósito não era referir-se ao fascismo político e ideológico de Estado, mas centralizar suas análises em descobrir as predisposições psicossociais para o fascismo latente em cidadãos comuns que não participavam de organizações políticas radicais. O perfil da personalidade autoritária ou do homem autoritário era um conceito relativamente novo e visivelmente presente nas sociedades modernas democráticas. A preocupação dos autores era descobrir os traços essenciais e históricos da personalidade potencialmente autoritária ou fascista que parece combinar as ideias e habilidades típicas da sociedade altamente industrializada com crenças irracionais ou anti racionais.

Freud, na década de 20 do século passado já havia diagnosticado que o mal estar na cultura nasce da repressão aos impulsos e desejos, sacrificando a felicidade humana e libertando os impulsos destrutivos do homem contra a civilização. Hoje nos deparamos com uma realidade diferente em que convivemos com uma abundância material e intelectual, em que aparentemente os impulsos e desejos podem ser satisfeitos, porém mantemos a sensação de um sentimento de claustrofobia, de que o mal estar não desapareceu, a pressão social tornou-se mais aguda e os níveis de violência cresceram em relação ao mundo administrado.

Cabe ressaltar que uma das questões relevantes nos estudos frankfurtianos é enfrentar a frieza contemporânea dos indivíduos que favoreceu a predisposição de comportamento fascista e entender o que o gerou. O princípio foi o anti semitismo, em que a prerrogativa é a do sujeito etnocêntrico que possui a predisposição para a discriminação e preconceito contra vários grupos étnicos. Ele sente-se cada vez mais envolvido numa rede densa de enclausuramento social e quanto mais densa é a rede, mais o indivíduo tenta se libertar. Contudo, essa densidade impede a saída. Isso libera as forças destrutivas contra a civilização, que se torna mais irracional e violenta.

O Indivíduo impulsionado pelo medo de não ser aceito pela coletividade, tende a aderir a ideias e ideais que permitem sua preservação imediata e o defende da destruição, idealizando como verdade absoluta, o grupo e sua liderança ao qual se identifica e rejeita, projetando qualidades negativas para qualquer ação, membro ou ideia de grupos ao qual não se identifica em forma de preconceito. Segundo Horkheimer e Adorno (1985), esse medo 


\section{Q DEVIR EDUCAÇÃO \\ ISSN: 2526-849X}

continua a existir na substituição do domínio da natureza sobre ele pelo domínio da sociedade, que nesse sentido, reage ainda a forças não civilizadas.

Quando este quadro se instala, o indivíduo fraco e impotente procura compensar sua fraqueza se identificando com seus opressores. Ele busca nas estruturas do poder uma identificação imaginária diante da sua insignificância e inaptidão frente a experiência que realimenta a personalidade autoritária que por sua vez nasceu da persistência dos pressupostos sociais objetivos que geraram o fascismo.

Os filósofos se propuseram entender os traços do fascismo e o preconceito com base em pesquisas sobre o indivíduo totalitário, àquele que é portador de uma estrutura relativamente rígida e constante, por um "reconhecimento cego, obstinado e intimamente rebelde tributado a tudo que se reveste de poder."(ADORNO \& HORKHEIMER , 1973. p.178). Um aspecto importante destacado pelos autores é que o pensamento do indivíduo é orientado hierarquicamente, submetido a autoridade moral idealizada pelo modo de vida social; ou seja ao grupo que supostamente julgam pertencer e colocando-se propensos a condenar, pelos mais diversos pretextos, aquele que não pertence ao seu grupo e, consequentemente considerado inferior. $\mathrm{O}$ indivíduo tende a idealizar o grupo e os líderes com os quais se identifica e projetar qualidades negativas, objeto do preconceito, nos grupos com os quais não se identifica. Desta forma, entende-se a manutenção da sociedade administrada atual por meio do indivíduo que é parcial ou plenamente alheios a ela.

Adorno e Horkheimer (1973, p.121) explicam que:

é preciso reconhecer os mecanismos que tornam as pessoas capazes de cometer tais atos, é preciso revelar tais mecanismos a eles próprios, procurando impedir que se tornem novamente capazes de tais atos, na medida em que se desperta uma consciência geral acerca desses mecanismos.

As palavras de Adorno, nos colocam diante da necessária "inflexão em direção ao sujeito" na sua relação social para estudar o preconceito e suscita tecer considerações sobre as disposições psicológicas para a disposição de tais atos no contexto de uma sociedade totalmente administrada onde os controles tecnológicos dissolveram o indivíduo autônomo. Devemos considerar que a lógica do capital nivela a tudo e a todos aos imperativos da economia. Nada escapa a mão invisível do mercado, que modela não somente os bens e serviços, mas também a alma humana. Afirmamos a real necessidade de pensar a moralidade 


\section{OO DEVIR EDUCAÇÃO \\ ISSN: 2526-849X}

dentro de uma perspectiva de entender o indivíduo em sua complexidade histórica e social, constituído não apenas de valores morais, como a justiça ou a generosidade, mas imbuído de sentimentos, pensamentos, anseios e desejos que se misturam continuamente.

Estamos diante de uma sociedade em que a opressão impõe-se como uma força devastadora, impedindo que os indivíduos vivam a autonomia e liberdade em sua plenitude. A realidade política, econômica e social determina o indivíduo em seu íntimo, naquilo que deveria ser o núcleo de sua autonomia. Nesta realidade em que estamos imersos "os sujeitos são impedidos de se saberem como sujeitos. A oferta de mercadorias que se abate qual avalanche sobre eles, contribui para isso, da mesma forma que a Indústria Cultural e incontáveis mecanismos diretos e indiretos de controle". (ADORNO apud MAAR, 2009, p.26).

A consequência desta organização totalitária do mundo capitalista é o enfraquecimento do indivíduo diante das forças opressoras abrindo portas para o surgimento das tendências fascistas e da personalidade autoritária na sociedade. Uma tendência que não é fomentada por ideologias políticas conservadoras, mas da impotência e da paralisia que incapacita o indivíduo a reagir frente a racionalidade opressora do mundo administrado.

É comum nesse caso, uma forma de pensamento, que para Adorno (1993) foi denominada de "natureza ciclista"- aquela que "na acepção metafórica de uma pessoa que gosta de calcar com o pé quem está por baixo e, ao mesmo tempo, dobra o corpo, em posição humilde, para os que estão em cima."(p.179). Para sobreviver, o indivíduo precisa se conformar e abrir mão da subjetividade autônoma, que está ligada a ideia de democracia adaptando-se e identificando-se com o existente e, assim fomenta a personalidade potencialmente autoritária. A atitude típica da personalidade autoritária e preconceituosa é ser ao mesmo tempo de dominação e submissão; domina àqueles que percebe mais fracos, e submete-se aos que percebe mais fortes.

Para assegurar a manutenção de sua hierarquia, a qualquer preço, este pensamento totalitário, apega-se à uma falsa segurança, proibindo toda e qualquer reflexão, com um único propósito: matar o diferente como se não houvesse qualquer outra alternativa. Desprezando assim, sua própria atividade intelectual, afetiva e criativa, afastando-se de sua responsabilidade pessoal e, que diz muito mais para o que sente preconceito, do que para seu alvo. Envolto no totalitarismo, o preconceito tende a destruir o indivíduo na sua plenitude, física e psiquicamente; jurídica e moralmente. O homem torna-se destruído na sua individualidade.

Revista Devir Educação, Lavras, vol.3, n.1, p.116-126 jan./jun., 2019. 


\section{QO DEVIR EDUCAÇÃO}

ISSN: 2526-849X

A tendência irracional de identificação com grupos sociais superiores e o realismo exagerado que não busca a compreensão do mundo pela razão, mas o reconhecimento de sua superioridade absoluta frente ao outro é uma das características da personalidade fascista que distorce a realidade, traduzindo-se em absoluta submissão ao existente. Para o fascista em potencial, cada indivíduo não tem outra escolha que não seja submeter-se "a uma adaptação que implica resignação perante a impossibilidade de lograr qualquer melhora essencial, que temos de abandonar todo o sonho e nos moldarmos até nos convertermos em um acessório a mais da máquina social.”(ADORNO, 1965, p.650).

A personalidade potencialmente autoritária ou com traços fascistas, no interior do pensamento adorniano nos conduz à compreensão e crítica do ajustamento social alienado que consiste também na análise da decadência dos processos formadores de cultura em sua caricatura unidimensionalizada pela semiformação. Pela vertente da análise de Adorno, a semiformação apresenta um aspecto central que remete diretamente às modalidades regressivas da personalidade pretensamente autoritária que é a esfera do ressentimento.

$\mathrm{O}$ ressentido e a rigor semiformado, volta sua hostilidade contra os fragilizados, os diferentes e os impotentes na hierarquia social, desviando, dessa forma, o rancor e a hostilidade contra a cultura, ao invés de entender os mecanismos de injustiça, frieza e desigualdade presentes na sociedade. Adorno (2000), mais do que aponta a reificação do pensamento fascista ao argumentar que um "esquema sempre confirmado na história das perseguições é a de que a violência contra os fracos se dirige principalmente contra os que são considerados socialmente fracos e ao mesmo tempo - seja isto verdade ou não - felizes." (p. 122).

\section{Preconceito, violência e Bullying na escola}

Após a análise crítica da personalidade autoritária e fascista, dos condicionamentos sociais e culturais que produzem o preconceito, bem como das necessidades psíquicas envolvidas nessas formas de violência, como o enfraquecimento da constituição do indivíduo que as desenvolve, tendo em vista o declínio da possibilidade de experiência nos últimos séculos é necessário nos voltarmos para o universo escolar, no intuito de desvelar o preconceito e estereótipos presentes nessa instituição, contribuindo assim, para a formação de educadores que vivenciam essa realidade promovendo a ampliação do debate e superação do mesmo.

Revista Devir Educação, Lavras, vol.3, n.1, p.116-126 jan./jun., 2019. 


\section{DEVIR EDUCAÇÃO \\ ISSN: 2526-849X}

As graves manifestações das tendências coletivas de acúmulo de impulsos violentos e preconceituosos reprimidos, cada vez mais presentes no cotidiano da escola, são relatados nos meios midiáticos: situações de brigas, estudantes portando armas, professores que são agredidos por alunos, situações que envolvem comportamentos hostis e intolerantes, configurando perseguições e bullying e tantos outros casos que fazem parte da rotina de algumas instituições escolares, provocando exclusão e discriminação, causando danos psíquicos e emocionais, além de comprometer as relações interpessoais e o desenvolvimento dos indivíduos inseridos nesses espaços. Tais tendências são agravadas na nossa sociedade em virtude do que Adorno (2000) denomina “claustrofobia das pessoas no mundo administrado", sendo este caracterizado como "rede densamente interconectada." (p.122)

Octávio Ianni (2004), denunciou a expansão do racismo, no século XXI, em escala mundial, nas diversas sociedades, que ao invés de retroceder, como era de esperar, tendo em conta as conquistas educacionais, se insere na dinâmica socioeconômica moderna com violência excludente.

É assim que o mundo ingressa no século XXI, debatendo-se com a questão racial, tanto quanto com a intolerância religiosa, a contradição natureza e sociedade, as hierarquias masculino-feminino, as tensões e lutas de classes. São dilemas que se desenvolvem com a modernidade, demonstrando que o "desencantamento do mundo", como metáfora do esclarecimento e da emancipação, continua a ser desfiado por preconceitos e superstições, intolerâncias e racismos, irracionalismos e idiossincrasias, interesses e ideologias (Ianni, 2004, p. 22).

Horkheimer e Adorno "Dialética do esclarecimento" alertavam sobre esse aspecto ao explicarem o desenvolvimento da civilização ocidental, o processo pelo qual o homem vence as trevas da ignorância, do preconceito e da submissão, mas

contudo, acreditamos ter reconhecido com a mesma clareza que o próprio conceito desse pensamento, tanto quanto as formas históricas concretas, as instituições da sociedade com as quais está entrelaçado, contém o germe para a regressão que hoje tem lugar por toda parte. Se o esclarecimento não acolhe dentro de si a reflexão sobre esse elemento regressivo, ele está selando seu próprio destino. Abandonando a seus inimigos a reflexão sobre o elemento destrutivo do progresso, o pensamento cegamente pragmatizado perde seu caráter superador e, por isso, também sua relação com a verdade. (HORKHEIMER\&ADORNO, 1985, p.13).

Revista Devir Educação, Lavras, vol.3, n.1, p.116-126 jan./jun., 2019. 


\section{QO DEVIR EDUCAÇÃO \\ ISSN: 2526-849X}

Podemos inferir, que o processo pelo qual o homem vence as trevas da ignorância, preconceito e submissão vem acompanhado do pensamento alienado, que despido de seu potencial emancipatório ante o domínio da razão técnica impede uma formação esclarecida e emancipatória. Horkheimer e Adorno ao refletir sobre a ambiguidade contida no conceito de progresso, inferem que o mesmo contém barreiras de exclusão e que os homens perderam o componente humano presente na cultura, apoiando-se numa conformação irracional.

Na obra Educação e Emancipação, Adorno discorre, entre outros, sobre a violência e a barbárie, filhas de uma racionalidade irracional, de conformações formais do pensamento produzidas e alimentadas pelo fracasso da formação e uniformização da sociedade administrada. Adorno está caracterizando o caráter manipulador da personalidade fascista como consciência coisificada, típica de pessoas que tratam a si próprias e ao outro como coisas. A violência é complexa, multifacetada, encontrando-se na sociedade sob as mais diversas formas, que se articulam, se conectam e se cruzam, sustentando pensamentos e ações marcados pela exteriorização de agressões físicas, que expressam o nível de intolerância que o preconceito pode causar, em que os indivíduos são julgados, maltratados, menosprezados e violentados por aparência física, cor, opção sexual, ou também pela violência psicológica, geralmente mais sutil, mas igualmente maléfica para a formação e constituição da subjetividade e identidade do sujeito.

A análise do preconceito e a violência na escola, permite-nos entender as bases psíquicas da servidão voluntária e como as representações da sociedade em que vivemos se reproduzem no cotidiano escolar - instituição que deveria ser o espaço de educação e socialização das crianças, mas que se transformou em espaço de agressão e desrespeito mútuo, com situações de preconceito, violência e bullying. Situações que não devem ser toleradas e, necessitam ser enfrentadas por professores, alunos, coordenadores e direção, com trabalhos educativos de desconstrução de estigmas.

Nosso maior temor é que Auschwitz se repita - e, neste sentido a escola não pode ser mais uma reprodutora da violência em relação aos impulsos destrutivos da barbárie que se refere à frieza implícita na educação nas atitudes violentas que tomam corpo e adeptos em efeitos catastróficos da primazia da violência coletiva sobre o indivíduo.

A condição social da escola é a de educar e socializar as novas gerações, sendo lugar de encontro e convivências múltiplas. É necessário a conscientização dos traços subjetivos presentes na cultura que propiciaram o advento do horror em que os efeitos catastróficos da primazia da violência coletiva caracterizado por Adorno (1995) como "pessoas que se 


\section{QO DEVIR EDUCAÇÃO \\ ISSN: 2526-849X}

enquadram cegamente em coletivos convertem a si próprios em algo como um material, dissolvendo-se como seres autodeterminados. Isto combina com a disposição de tratar outros como sendo uma massa amorfa." (p. 129).

Contudo, atualmente ao invés de ser um lugar de construção e fortalecimento dessa convivência, tornou-se palco de agressão, desrespeito mútuo, bullying e preconceito. Destacando aqui, nossa intenção de ressaltar as diferenças entre bullying e o preconceito como apresentados por Crochík (2015):

o bullying parece ser uma forma de violência mais indiferenciada do que a presente no preconceito mais arraigado, que tem alvos definidos e justificativa para sua existência, e corresponder a uma maior fragilidade do indivíduo que o pratica; nesse sentido, o preconceito menos delineado pode ser a atitude que pode levar à ação do bullying; esse também parece expressar melhor uma cultura homogênea, que, pela (falsa) formação, constitui indivíduos frios, insensíveis e com dificuldades de formular seus desejos e os reconhecer, o que pode direcioná-los a uma forma de violência difusa, ao contrário do preconceito que se fixa em necessidades mais bem delimitadas. (p. $54)$.

Como vemos, o preconceito se caracteriza pela justificativa de dominação, pela perseguição de indivíduos ou grupos pertencentes a minorias sociais; o bullying se apresenta como uma violência e se manifesta devido à intolerância e a não aceitação do outro que é diferente, sendo marcado por constantes agressões físicas e psicológicas, praticada por um ou mais indivíduos.

A escola deve ter a capacidade e discernimento de admitir a existência do problema, que o preconceito, a violência e o bullying existem é o primeiro passo para que se possa buscar soluções e alternativas de enfrentamento ao mesmo. Dessa forma é importante que no processo formativo, educadores e educandos sintam-se parte do mesmo processo, no sentido de conseguirem identificarem as pessoas com potenciais traços sádicos reprimidos e que se manifestam, verbalmente, quando, segundo Adorno (2000) "algo é criticado ou exigido", e se torna "ameaçadora, como se os gestos e a fala fossem de uma violência corporal quase incontrolável" (p. 127). Tendo uma construção social e não inata, a violência pode ser combatida com ações que demandam, segundo Adorno (2000) "autonomia, o poder para a reflexão, a autodeterminação, a não participação" (p. 125). Acreditamos que a educação verdadeiramente humana - que rompa com a competição desenfreada, com a banalização da 
violência, com ações de agressividade, que redundam em preconceito, violência e bullying - é emancipatória.

\section{Referências}

ADORNO, Theodor W. et. al. La personalidad autoritaria. Buenos Aires: Proyección, 1965. p. 567728.

ADORNO, Theodor W. Educação e Emancipação. 3. ed. São Paulo: Paz e Terra, 2000.

ADORNO, Theodor W. Educação após Auschwitz. In: ADORNO, Theodor. Educação e Emancipação. 3. ed. São Paulo: Paz e Terra, 2000.

CROCHÍK, José Léon. Formas de violência escolar preconceito e bullying. Movimento: Revista de Educação. Faculdade de Educação. Programa de Pós-Graduação em Educação. UFF. Ano 2, número 3. 2015.

CROCHÍK, José Léon. Preconceito, indivíduo e cultura. São Paulo: Casa do Psicólogo, 2006.

HORKHEIMER, Max. Preconceito. In: ADORNO, Theodor; HORKHEIMER, Max. Temas básicos de sociologia. São Paulo: Cultrix, 1973. p. 172-183.

HORKHEIMER, Max. Dialética do Esclarecimento: Fragmentos filosóficos. Rio de Janeiro: Jorge Zahar, 1985.

IANNI, Octávio. Dialética das Relações Raciais. Revista Estudos Avaçados. São Paulo, v. 18, n. 50, 2004.

MAAR, Wolfgang. L. A formação da sociedade pela indústria cultural. In: Revista Educação, Coleção Especial: Biblioteca do Professor, Adorno pensa a Educação. São Paulo: Editora Segmento, ano 2, n. 10, p.26-35, 2009. 